\title{
The Effectiveness of Professional Development in Overcoming Obstacles to Effective Online Instruction in a College of Education
}

\author{
Jered Borup and Anna S. Evmenova \\ George Mason University
}

\begin{abstract}
Growth of online learning has placed increased pressure on K-12 schools and universities to provide students at all levels with qualified instructors. It is especially important that colleges of education provide pre- and in-service teachers with skilled online instructors so that they can experience the benefit of quality online instruction firsthand as students. This case study examined the effectiveness of a 6- to 7-week professional development course designed to improve faculty members' knowledge, skills, and dispositions - all required to teach online effectively in a college of education. Faculty participants were also given the opportunity to earn up to seven digital badges for demonstrating specific skills during the professional development course. Analysis of 18 faculty interviews, surveys, and discussion board comments found that course content and assignments improved faculty members' knowledge and skills, but the ways the course was delivered and the online teaching methods modeled by the course instructor appeared to have a larger impact on perceptions and attitudes towards online learning. As a result, online teaching professional development may have its greatest impact when it models the types of online courses the college would like faculty themselves to design and facilitate. Faculty appeared to be more motivated to earn digital badges than they had originally anticipated, but were confused about what to do with the badges once they were earned.
\end{abstract}

Keywords: online learning, online teaching, instructor modeling, professional development

Borup, J. \& Evmenova, A.S. (2019). The effectiveness of professional development in overcoming obstacles to effective online instruction in a college of education. Online Learning, 23(2), 1-20. doi:10.24059/olj.v23i2.1468

\section{The Effectiveness of Professional Development in Overcoming Obstacles to Effective Online Instruction in a College of Education}

Online learning has grown dramatically over the past 20 years in both K-12 and higher education settings (Allen \& Seaman, 2017; Gemin \& Pape, 2017). This has created a high demand for quality online teachers at both levels. Research has found that teaching online requires different competencies, and skilled face-to-face teachers do not necessarily make quality online teachers (Barbour, 2012). Unfortunately, teacher preparation programs in colleges of education have been slow to respond to this growing need, and few preservice teachers take coursework that helps them gain the skills required to teach online (McAllister \& Graham, 2016). As a result, the only 
experience that many pre- and in-service teachers have with online learning is as online students themselves. Research has found that pre- and in-service teachers can gain insights into online teaching strategies by observing their own online teachers (Norton \& Hathaway, 2015). However, colleges of education have struggled to prepare quality instructors for their online courses, and their online teachers do not always model the most effective online teaching practices to their preand in-service teachers (Myer \& Murrell, 2014). As a result, it is especially important that colleges of education ensure that their online instructors not only can teach online course content effectively but also are able to model optimum online teaching practices that can help their students envision online learning's potential.

What are considered online teaching best practices have also evolved with the available communication technology. Anderson (2009) stated, "technologies have developed, distance education has evolved in parallel to support new forms of interaction, pedagogy and support services" (p. 111). The Internet has caused the most dramatic evolution in distance education. Prior to the Internet, distance education focused on learner independence and learner-content interactions. Faster Internet speeds have enabled more collaborative and constructivist learning (Garrison, 2009). However, these new possibilities do not guarantee a change in practice, and many instructors simply use the Internet to transmit information and assess students' understanding of that material. Similarly, a national review of K-12 online charter schools found that the majority rely primarily or exclusively on an independent study model that focuses on students' interaction with the content and teacher-not other learners (Woodworth et al., 2015). Garrison (2009) argued that, instead, online courses should be "less about bridging distances and more about engaging learners in discourse and collaborative learning activities" (p. 94).

Moore (1989) was one of the first researchers to identify learner-learner interaction as a primary component of distance education, stating that it is "sometimes an extremely valuable resource for learning, and is sometimes even essential" (p. 4). Garrison, Anderson, and Archer's (2000) Community of Inquiry (CoI) framework helped to explain why learner-learner interactions are a critical component of students' learning online. The framework was founded in principles established by John Dewey and viewed learner-learner interaction as the means by which students collaboratively construct knowledge of course content. Swan, Garrison, and Richardson (2009) explained, "Higher education has traditionally emphasized constructivist approaches to learning in the sense of individual students taking responsibility for making sense of their educational experiences. What is less common is the collaborative construction of knowledge in a community of learners" (p. 43). While distance education and online learning are commonly used interchangeably, Garrison (2009) saw courses that prioritized independence and flexibility as distance education and defined courses that prioritized a collaborative constructivist view as online learning. While not everyone accepted this distinction, most notably Anderson (2009), it does provide a helpful definition for online learning, one that we accepted for this research. This shift from independent study to collaborative constructivist ways of learning requires faculty not only to develop technological and pedagogical skills unique to collaborative online learning environments but also to believe that a shift to more interactive and collaborative online learning would be beneficial to their students.

In this case study, we analyzed faculty surveys, discussion board comments, and interviews to examine the effectiveness of a 6- or 7-week professional development course designed to prepare faculty members to teach online courses. More specifically, we addressed the following questions: 
- What perceived impact did the professional development have on participants' knowledge and skills required to teach online?

- What perceived impact did the professional development have on participants' perceptions and attitudes toward online learning?

\section{Review of Literature}

In this section, we will first discuss barriers to online teacher professional development that need to be overcome to create a meaningful impact on faculty members' ability to design and teach online courses. We will then review the research examining faculty professional development initiatives.

\section{Barriers to Change}

Ertmer (1999) identified and defined first-order and second-order barriers to change. While Ertmer originally focused on classroom teachers' use of technology, we argue that this framework should also be considered when designing online teacher professional development initiatives. In this section we will discuss both types of barriers in relation to online teaching.

First-order barriers. First-order barriers are external to the instructor and include access to technology, time constraints, and professional development opportunities to improve knowledge and skills. For the purposes of this article, we focused on the latter.

In order to provide professional development, universities must first identify the knowledge and skills required to effectively teach online. Shulman (1986) was one of the first researchers to categorize the types of knowledge needed for teaching. Shulman believed that teachers' content knowledge (CK) and pedagogical knowledge (PK) were not mutually exclusive domains and that CK and PK were interrelated. Shulman (1986) explained that teachers are required to have an understanding of the content that extends beyond "the dimension of subject matter knowledge for teaching" (p. 9). Similarly, teachers develop knowledge of general pedagogies that are effective regardless of the content being taught, as well as content-specific pedagogies. As a result, Shulman introduced the concept of pedagogical content knowledge (PCK) to describe the areas where teachers' PK and CK intersected.

Mishra and Koehler (2006) added technological knowledge (TK) to Shulman's framework and explained how TK interplayed with PK, CK, and PCK. By adding TK, Mishra and Koehler (2006) actually added four types of knowledge to the framework:

- Technological knowledge (TK): "Knowledge about standard technologies, such as books, chalk and blackboard, and more advanced technologies, such as the Internet and digital video" (p. 1027).

- Technological content knowledge (TCK): "Knowledge about the manner in which technology and content are reciprocally related" (p. 1028).

- Technological pedagogical knowledge (TPK): "Knowledge of the existence, components, and capabilities of various technologies as they are used in teaching and learning settings, and conversely, knowing how teaching might change as the result of using particular technologies" (p. 1028). 
- Technological pedagogical content knowledge (TPACK): “[A]n understanding of the representation of concepts using technologies; pedagogical techniques that use technologies in constructive ways to teach content; knowledge of what makes concepts difficult or easy to learn and how technology can help redress some of the problems that students face; knowledge of students' prior knowledge and theories of epistemology; and knowledge of how technologies can be used to build on existing knowledge and to develop new epistemologies or strengthen old ones" (p. 1028-9).

While Shulman's (1986) PCK framework already addressed teachers' understanding of instructional materials, such as "software, programs, visual materials, single concept films" (p. 10), Mishra and Koehler's (2006) TPACK framework placed a greater emphasis on educational technology and was warmly welcomed by the educational technology community. However, in practice it has proved difficult to distinguish between elements such as TPK and TPACK, which has caused some to question the validity and utility of the framework (Graham, Borup, \& Smith, 2012; Archambault \& Barnett, 2010; Graham, 2011).

The TPACK authors also emphasized that specific types of knowledge are "context bound" and dependent on variables, such as the content taught, student background, and level taught (Mishra \& Koehler, 2006, p. 1032). By its nature, the online learning environment changes the types of required pedagogical and technological knowledge and skills. For instance, Mishra and Koehler (2006) explained that asynchronous online environments "force an online instructor to develop other ways to represent content and thus impact pedagogy" (p. 1030). Similarly, the online environment can change how instructors interact with students, foster a sense of community, motivate student engagement, provide feedback on course projects, and facilitate learner-learner discussions and collaboration (Baran, Correia, \& Thompson, 2011; Bigatel, Ragan, Kennan, May, \& Redmond, 2012; Park, Johnson, Vath, Kubitskey, \& Fishman, 2013). Because the "skills to teach in an online environment cannot be assumed to transfer automatically from skills in teaching a face-to-face classroom," instructors should be provided with professional development that prepares them for the specific challenges they will face online (Barbour, 2012, p. 504).

Second-order barriers. Second-order barriers are internal to the instructor and include beliefs about teaching and learning, attitudes toward change, and self-efficacy. Ertmer (1999) explained that whereas first-order barriers are relatively easy to identify and overcome once resources are secured, second-order barriers are difficult to identify and overcome because "they are more personal and more deeply ingrained" (p. 51). In fact, they may not even be known to the instructors themselves.

One way to change instructors' attitudes towards online teaching and learning is to engage them in online professional development experiences that effectively model the benefits and possibilities available in the online learning environment (Elliott, Rhoades, Jackson, \& Mandernach, 2015). Following Bandura's (1986) social cognitive theory, instructors can learn new behaviors by observing someone else perform those behaviors and then imitating them. The effectiveness of social models in changing others' behaviors, beliefs, and attitudes is based on both observations of models and social interactions (Bandura, 1997; Gachago, Morkel, Hitge, van Zyl, \& Ivala, 2017). As a result, professional development is most effective when participants are provided opportunities to exhibit the behaviors they have observed. These hands-on application experiences make them relevant and authentic to their own teaching (Gosselin et al., 2016; Johnson, Wismiewski, Kuhlemeyer, Isaacs, \& Krzykowski, 2012). They also provide secure space to explore the technology and experience satisfaction with its affordances, while observing best 
practices implemented by the instructor (Walters, Grover, Turner, \& Alexander, 2017). The combination of observation and active process of doing is an important component when preparing online instructors and advocates (Gachago et al., 2017). In addition to the instructor models, Bandura and Kupers' (1964) seminal research found that peer modeling can impact others' motivations and behaviors. As a result, professional development that facilitates learner-learner interactions may be particularly effective at changing participants' attitudes and perceptions of online learning.

\section{Professional Development Approaches and Outcomes}

While the topic of preparing faculty for online teaching is popular in the literature, many studies focus on what to teach rather than how to teach it. Faculty professional development can occur in both synchronous and asynchronous online courses (Dyjur \& Lindstrom, 2017; Ginzburg, Chepya, \& Demers, 2010; Rienties, Brouwer, \& Lygo-Baker, 2013; Schrum, Burbank, Engle, Chambers, \& Glassett, 2005) that establish online learning communities or focus more on independent, flexible learning (Brooks, 2010; Reilly et al., 2012). Professional development can also be provided as boot camps, seminar series, minicourses, webinars, hands-on workshops, peer training, or meetings with experts (Gosselin et al., 2016; Johnson et al., 2012; Meyer \& Murrell, 2014; Reilly, Vandenhouten, Gallagher-Lepak, \& Berg, 2012; Roby, Ashe, Singh, \& Clark, 2013; Signer, 2008; Wang, 2007). These professional development opportunities can be more meaningful if they are designed based on the content that participants find applicable and useful (Walters et al., 2017). Some researchers also support the idea of individualized and customized training (McQuiggan, 2012; Rhode, Richter, \& Miller, 2017; Wingo, Peters, Ivankova, \& Gurley, 2016), while others emphasize the importance of regularly scheduled, standardized trainings (Meyer \& Murrell, 2014).

However, only a few existing studies relied on modeling best practices for online teaching and learning through the delivery of online professional development. This is consistent with the overwhelming prevalence of face-to-face delivery of online teacher professional development as described in a national study of 39 higher education institutions (Meyer \& Murrell, 2014).

While it might take some instructors longer to adopt online teaching (e.g., McQuiggan, 2012), the aforementioned studies reported that online professional development increased knowledge and improved faculty perceptions. For instance, Ginzburg, Chepya, and Demers (2010) reported that the majority of faculty felt confident in their ability to develop and teach in an online environment after an 8-week online cohort program. In their study, cohorts consisting of 8-14 faculty members participated in the course led by staff from the Office of Instructional Technology. The authors attributed positive learning outcomes to the fact that faculty were able to experience online learning from the perspective of a student. Rienties, Brouwer, and Lygo-Baker's (2013) analysis of pre- and posttests found that, in addition to increased confidence, the 33 participants demonstrated significant increases in TPACK knowledge following completion of four online modules designed to improve faculty's ability to teach online. The modules were designed to last 8-12 weeks, allowing flexibility and autonomy for instructors to complete the work and reflect on their progress. Similar improvements in TPACK as well as increased satisfaction were found in another study by Rienties et al. (2013). As online learning technology continues to develop, little information exists on the effectiveness and preference of an online format to foster interactive professional development for instructors preparing to teach online (Elliott et al., 2015; Norton \& Hathaway, 2015). 


\section{Methods}

Merriam (1998) explained, "Qualitative researchers are interested in understanding the meaning people have constructed, that is, how they make sense of their world and the experiences they have in the world" (p. 6). Stake (2010) added that qualitative researchers seek understanding and then work to improve "how things work" (p. 14). Merriam (1998) distinguished case studies from other types of qualitative research because case studies focus on a single, bounded unit or system. However, it is important to note that case studies are not simple and are what Wolcott (1994) called "complex specificness" (p. 107). For this case study, we set our boundaries of inquiry around a new online teaching initiative at a single college of education.

\section{Context and Setting}

This case study was conducted at a large mid-Atlantic university's college of education. Guided by Quality Matters rubric standards, the college developed the Online Teaching Initiative (OTI) course to help prepare faculty to teach online courses that are primarily delivered asynchronously with learner-learner interactions and collaboration. The OTI course was delivered asynchronously with weekly assignment deadlines. The first module oriented participants to the course design and calendar as well as to general trends in online learning. The orientation module also required participants to sign up for a Google Drive account, download a screencasting tool to be used in later modules, and access their learning management system (LMS) course sandbox they would later use to demonstrate competency of certain skills. Participants were also introduced to the OTI digital badges used to certify their competency in various areas of online teaching. Once students earned all six digital badges, they were awarded the Online Teaching Essentials badge (see Figure 1).

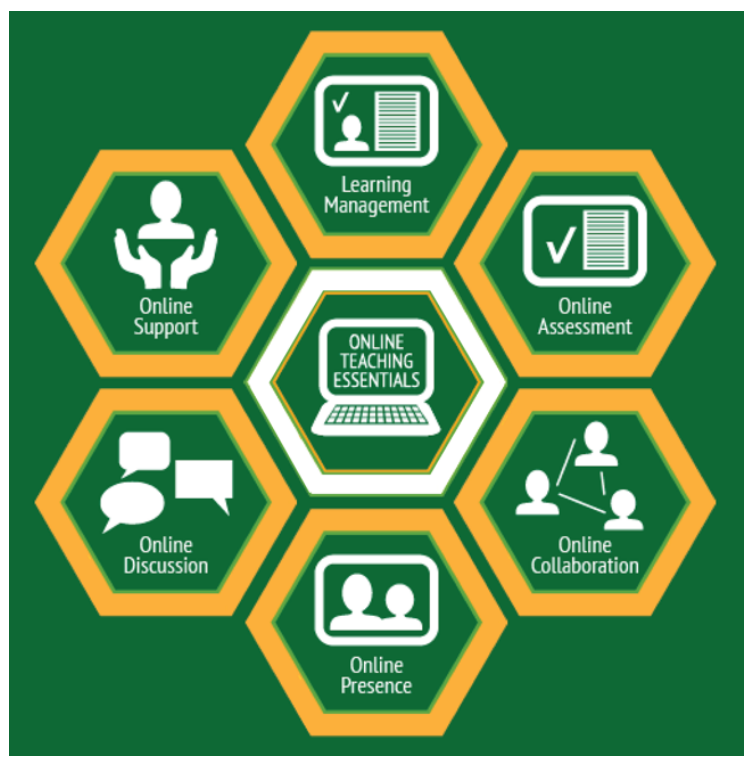

Figure 1. Image showing the digital badges that were available for participants to earn. The university name has been removed.

Following the introductory module, the remaining modules addressed the following topics concerning online instruction: (1) course design and development, (2) assessment and feedback, (3) student collaboration, (4) discussions, and (5) presence and support. Each module contained 
lessons and workshops designed to help faculty develop new knowledge and skills required to teach interactive online courses. Lessons commonly had examples from online faculty and students. Where possible, the examples came from teachers and students within the college of education.

To earn the accompanying digital badge, participants needed to submit learning artifacts. If mastery was not demonstrated, they received feedback from the instructor that they could apply to their project until they demonstrated mastery. Participants could test out of the workshops if they had mastered and demonstrated a given skill previously while teaching an online course. The majority of the workshops required participants to perform tasks within their LMS course sandbox, but the OTI course also required them to use tools external to the LMS.

Participants were organized into small learning groups, each containing four to five people. They then interacted regularly with their group members in discussion board activities where they shared beliefs about and perceptions of what was being taught. Participants also engaged in peerreviews of the learning objects created as part of the workshops. They worked in collaborative teams to complete one of the workshops using Google Drive. In an attempt to establish a trusting learning community, participants engaged in an icebreaker discussion board activity that required them to create and post a video introduction and then view and reply to their fellow group members' video comments.

\section{Data Collection and Analysis}

The OTI course was originally offered during a summer semester as a 7-week course and was then offered the next year during the summer and fall semesters as a 6-week course to better accommodate faculty members' schedules. The course content and design remained consistent across all course offerings. Each course offering had eight completers, for a total of 24 completers. In total, seven participants started the initiative by posting at least one comment in the icebreaker discussion but did not finish the initiative and were excluded from this research.

Data were collected using surveys, conducting interviews, and collecting discussion board comments. Specifically, pre- and postcourse surveys were used to measure changes in participants' knowledge and skill development. Discussion board comments and interviews were used to better understand their experiences and perceptions.

Participants' knowledge and skill development was measured using Archambault and Crippen's (2009) survey instrument designed to measure the "skills that online teachers should know and be able to do" (p. 75). The survey items were based on the TPACK framework and used a six-point response scale (from $1=$ strongly disagree through $6=$ strongly agree). However, only the items related to TK, TCK, TPK, and TPACK were used for this research. All OTI participants were invited to take a survey before they actually began the course and again when they finished. All course completers were also asked to participate in a 30-45 minute interview.

Survey responses were analyzed using descriptive statistics. Interview transcripts were analyzed using elements of constant comparative coding methods (Glaser, 1965). Following Glaser's (1995) recommendation, the primary author coded faculty interview statements into as many categories as possible while comparing each statement to previous coding categories. Categories were then combined into larger themes guided by Ertmer's (1999) first- and secondorder barriers of change. The coding was then reviewed by the second author, and any disagreements were discussed until resolved. Lastly, participants' discussion board comments in 
response to their final discussion prompt were analyzed using the same process. The discussion prompt asked participants to reflect on what they had learned and to share any previous misconceptions regarding online learning, if any.

\section{Results}

Of the 24 participants who completed the initiative, 21 completed the pre- and postcourse survey, and 18 (16 female) participated in an interview. Of the 18 interview participants, half were adjunct instructors. Five of the adjuncts had earned a $\mathrm{PhD}$, and four had earned a master's degree. Of the nine full-time employees, three were associate professors, and six were assistant professors. Participants were split evenly between those with online teaching experience and those who had never taught online. Of the nine participants with online teaching experience, one had only taught online "many years ago," and three had only taught synchronous online courses.

Although the small sample size prevented inferential statistics from being used, descriptive statistics of survey responses showed increases in participants' TPACK $(+1.23, S D=0.69)$, TPK $(+1.07, S D=0.77)$, and TCK $(+0.85, S D=0.73)$. Participants' TK also increased on average, but the change did not appear to be as meaningful $(+0.19, S D=0.72$; see Figure 2$)$. The average change in TK also has a standard deviation higher than the mean increase, indicating a large variance across participants.

\section{Pre- and Post-test Comparison}

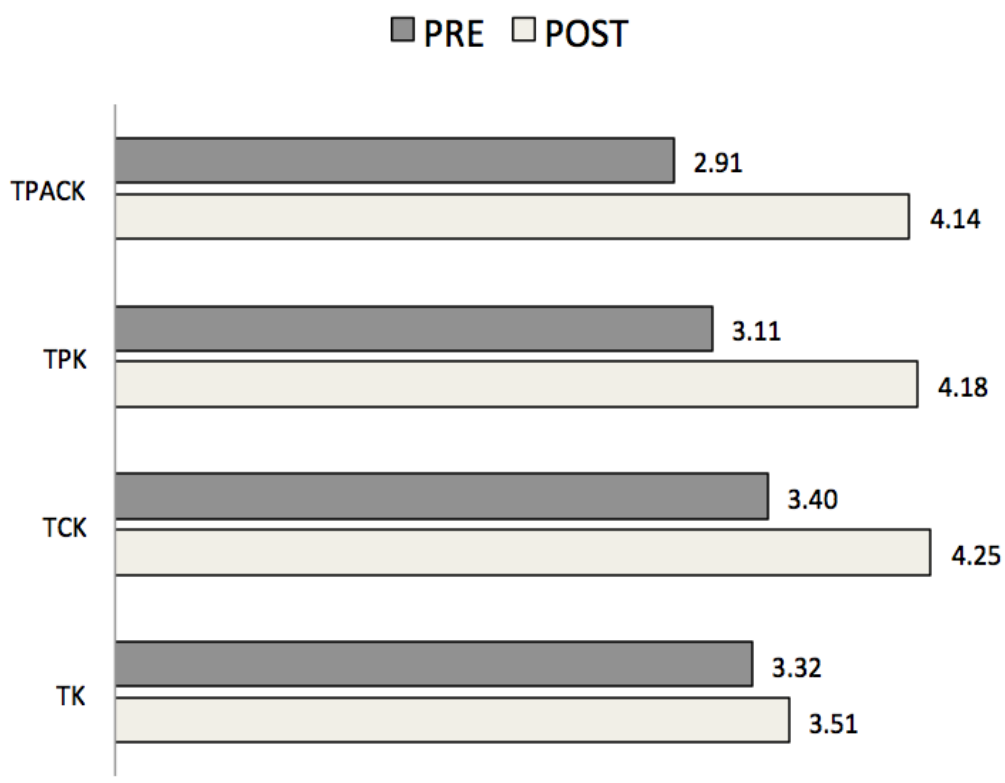

Figure 2. Comparisons between participants' pre- and postcourse surveys reported levels of their TPACK, TPK, TCK, and TK. Survey items used a six-point scale (from 1 = strongly disagree through 6 = strongly agree).

The remainder of the section will discuss results from the interview and discussion board analysis. First, we will present the findings related to how the OTI course impacted participants' pedagogical knowledge and technological knowledge. Following, we will share the findings 
related to participants' motivation to engage in learning activities and describe how that engagement impacted their perceptions of online learning.

\section{Impact on Pedagogical Knowledge}

Similar to their survey responses, analysis of participants' interviews and discussion board comments found that the course helped improve their online pedagogical knowledge (PK). Participants most commonly attributed their increase in PK to the online lessons that contained various examples as well as to their discussions with peers.

Interview participants commonly explained that the instructor and student examples embedded in the online lessons were especially valuable because they "opened up to [them] different online options." Participant 4 stated, "It made more sense seeing a finished product, or what it would look like from a student. I thought that was very helpful. ... It was too abstract without them. It was helpful to see specifics." Participant 8 added that the multiple student and instructor examples were "very helpful so you got to see other ways to do it. Something I would not thought of probably." For instance, Participant 3 recalled her reaction to viewing a video feedback comment an instructor had created for her students, "Woah, you can give feedback like that? That is so cool! Yeah, all of those examples were incredibly good. ... I loved his examples." Participant 12 explained that the student and teacher examples distinguished the OTI course from previous professional development "mini classes" that the university offered to faculty:

I did one or two of those [mini classes offered by the university] and they were helpful, but not in the way that the OTI class was, just really hands-on and lots of different ideas and actually showing you examples. I thought that was helpful.

Participants also found that their discussions with peers allowed them to expand their PK. Participant 11 stated that "[my group members] were designing rubrics differently. That's just interesting, just to see how they do it over in [their content areas]." Participant 5 found that his group members would "approach [tasks] completely differently" and appreciated the "opportunity to absorb other people's ideas." Participant 15 also explained that discussions with her peers allowed her and others to "get more ideas to use in the future for your toolbox." Participant 7 added that opinions from peers were especially helpful "instead of an expert's [opinion]" because "they were all colleagues and so they all kind of knew what we were going through."

\section{Impact on Technological Knowledge}

While the lessons and discussions helped to increase participants' online PK, the weekly workshops tended to improve participants TK because they required participants to use technological tools to put into practice some of what they had learned in the lessons. Similar to the survey findings, the interview analysis found that participants varied in their incoming abilities. On the survey and in his interview, Participant 12 reported a high level of technological knowledge. He also shared that prior to the course he was comfortable using the same tools "over and over again" but found that the course "just went a little deeper." He summarized, "That's basically the whole class. There might be one way that you're comfortable with right now but there are two other ways that you can do it that may be more effective." Participant 11 added that before the course she "found it very easy" to perform some online instructional activities, but she was still "learning new things for the first time."

Those with lower incoming technological skills found that "the learning curve was huge." Participant 4 explained that the workshops "kind of stressed [her] out" because she "didn't have a 
lot of skills." Participant 15 shared the following:

[The workshops] made me stand on a cliff and look down and have to jump, on the edge going, "Oh, shoot! I haven't done this before." ... It just challenged me. It pushed my boundaries. It pushed me to do things I hadn't done on the computer before. So yeah, every week it was frustrating but I felt good afterwards.

Interview participants also explained that the course "opened [their] eyes" to new tools that made them realize they had more to learn than they originally thought. This unexpected exposure to new technologies may help explain why there was only a slight increase in participants' TK as indicated on the survey. For instance, Participant 13 stated that before the course she "thought [she] knew some things," but after the course she realized that she was "just scratching the surface." Similarly, some participants admitted that it was difficult to adequately rank their technological abilities because they "still don't know what [they] don't know."

While interview participants all believed that the OTI had helped prepare them to teach online, they also commonly expressed a need for additional support. Participant 4 added that while her TK had increased during the course, she remained uncomfortable using some of the technologies: "I think I have the knowledge. I think for me it's just about building confidence and efficiency, so that it doesn't take me forever to build a module or a workshop." Participant 11 also shared, "I need to practice a lot. Doing it once is great but I do not feel like I've mastered the skill without applying it again and again." As a result, interview participants commonly explained that they were happy that the course remained open for them to access after the course had ended. Participant 17 shared, "I've referred back to [the course]. I'm so glad I still have access to it because I go back to it quite a bit." At the time of her interview, Participant 13 had not returned to the course but anticipated that she would most likely return to it when she was actually teaching online or, as she put it, "going from the sandbox to real life." Another participant suggested that more advanced courses should be offered to those who have finished the OTI course.

Participants' discussion board comments mirrored those shared in interviews. The most common realization that participants shared was the number of technologies outside of the LMS that could be integrated into their online course. One participant who had no previous online teaching experience commented, "The breadth of online resources/tools can be overwhelming.... After week 2, I thought I had learned so much ... but after week 5 - wow!" Even a participant who had "been teaching online for a while" appreciated being shown new technologies. She stated, "I love that this course exposed me to new tools, and moreover, made me play with them. I am now much better equipped to use a variety of tools that will definitely increase student engagement." Similar to their interview comments, several indicated on the discussion board that they would be "returning to the course for reference in the future, again and again." Although the course remained open, one discussion participant was "a little worried about forgetting some of the options." Another participant then suggested creating a "chart which lists the options, programs, etc." Following that suggestion, participants actually created a table and shared with it others in the course.

\section{Impact on Participant Confidence and Motivation}

Participants' confidence and motivation increased following successful experiences in the course. For instance, in her interview Participant 21, who found that "everything was new" in the workshops, stated, "Every time I finished something I would go "Wow, look at what I learned to 
do. I've never known how to do that before.' For me that was a little fabulous." Similarly, in the discussion board one participant stated the following:

[I] didn't really believe that I would learn enough in only 6 weeks to make me feel confident enough to design my own courses. I know that there is a tremendous amount still to learn, but do feel like I know enough to get off to a good start.

A discussion board participant who stated that she was not a "techie sort of person," found it "very satisfying" when she completed workshop activities, which resulted in "improved confidence." Another summarized that she was "much more prepared and enthusiastic" to teach online after completing the workshops.

Just as the workshops improved student confidence and motivation to teach online, participants identified factors that motivated them as students to complete the OTI, which, in turn, helped them to better understand how to motivate their future online students. First, their interactions with the instructor motivated them to complete the OTI course. For instance, Participant 16 stated that she "loved interacting with the instructor," and Participant 15 explained that her interactions with and feedback from her instructor were "very inspirational" because "he has a great personality, and he made it fun." Participant 8 added that instructor-created tutorials "were a little more personal" than Blackboard provided tutorials, and she "related to that more." A discussion board participant added that her interactions with the instructor were helpful because "he always sounded so excited and upbeat."

Learner-learner interactions had a similar motivational effect. Participant 10 believed the course "would have been pretty boring" without learner-learner interactions, and Participant 15 went as far as saying that without her interactions with peers, she "probably would have fallen out" and "appreciated that there were others that we had to interact with." Participant 7 found that she became more motivated to learn the content when she perceived "the enthusiasm of the other individuals within [her] group as they were learning something for the first time." One discussion board participant found that it "was really fun being in a group" and was "excited to try [student collaboration and discussions] in [her] own class." Another participant replied that previous to taking the OTI course she "didn't really see the value in discussions boards" and "had stopped using them." However, after participating in discussion boards as a student, she was "thinking about how [she] can apply some of what we have learned to [her] fall course load."

However, there were some drawbacks to discussions and collaboration. Participant 11 felt frustrated during the collaborative workshop because she was "dependent on someone else's time" and did not enjoy "the regular annoyances that you have with the group work." Participant 21 acknowledged similar drawbacks to collaborative projects in the course but also stated that "when it went well, it was kind of fun." Participant 12 also understood that online discussions and collaboration could be frustrating but admitted that he "didn't really have the frustration because [he] was able to look through the discussion boards and see that everyone had their own issues, or own questions, or own level of understanding."

The majority of participants were also motivated to earn the digital badges that were awarded to those who successfully completed all of the workshop criteria. Participant 10 explained, "I'm competitive and I want to do well so I certainly wanted to make sure I earned [the badges]." Participant 13 added, "I was very motivated to earn the badges. ... It was sort of like when we were younger and we were Scouts or Campfire Girls or whatever, and you earned your badges and you were really proud of displaying it." Participant 16 was "surprisingly excited at 
having badges" but, similar to others in the course, was confused at what to do with them once they were earned: "I don't understand where to put them. [The instructor] talked about putting it on some sort of backpack sort of thing. I didn't know that I had one of those yet." Similarly, Participant 21 described the badges as a "grownup token economy" and was highly motivated to earn them, but "afterwards when it's over, I don't know how they serve me." Participant 8 summarized, "I can't believe this but yes I was [motivated to earn the badges]. I haven't done anything with them but I got them all."

\section{Impact on Perceptions and Teaching}

In general participants agreed "the class itself really changed [their] perspective of online learning" because it provided them with "a student's perspective." Participant 18 appreciated the opportunity to "feel like how it was to be a student in that class with other peers," and Participant 17 found that being an online student allowed her to know "how long it is going to take" her students to complete learning activities. Participant 3 added that being a student helped her recognize features that were not provided in the course but would have been helpful: "Having a [task] checklist, I think, would be really helpful." Similarly, in the discussion board activity, one participant found that taking an online course changed the way she would design her online courses: "Because of this, as I design my course, I am constantly thinking about it from a student perspective."

Analysis of interview responses found that the course provided "a good model for a good course instruction and good design" that was especially impactful on changing participants' perceptions and attitudes towards online learning. Participant 16 explained,

There was really the close alignment of what we read with what was modeled and what we were expected to do. And I think that's the best kind of learning. It's not, "Do what I say, not what I do." But as we were learning a particular topic, then it would be modeled, demonstrated.

For instance, Participant 21 found that the course layout "taught us as students how to implement some of those ways to make [our courses] a little more creative," and Participant 23 "basically kind of mimicked a lot of how [the OTI] course was set up in Blackboard."

Participant 16 shared that participating in the course as a student "reprogramed" her when she realized that "online learning doesn't need to be a replication of classroom learning." A discussion board participant explained that prior to taking the OTI course she viewed online learning as primarily narrated presentation slides and quizzes. However, the OTI course was designed in a way that showed her that online learning could be "fun" and "was vastly different from what [she] had been accustomed to." Another discussion board comment read, "Taking this course has exposed me to how [online learning] could be: engaging and interactive." A different discussion board participant who had online teaching experience explained it this way:

I probably would have naturally stuck to the typical way I've been facilitating my online courses, if I hadn't been pushed to try/see new things through this initiative. Now, that I have, I feel it was very worthwhile, and I have a lot of new good ideas.

Another participant agreed that the OTI course had "really opened [her] eyes to the possibilities of online learning" and believed that online learning could be "more engaging than the traditional types of learning activities that often take place in face-to-face classes."

In the discussion board activities, students commonly shared that they were surprised at 
how difficult it was to learn online. For instance, one participant who had "many years of teaching online classes ... still had one main misconception: that [she] could sign up for this additional course and it would not increase [her] workload very much because it is 'just an online class."' Another discussion board comment stated, "Prior to taking the OTI, I thought [online learning] was an easy way out for lazy students" but came to realize that learning online required hard work and dedication. The rigor they experienced as online students also appeared to help them realize that teaching online would be just as rigorous as teaching face-to-face courses - if not more so. One participant admitted wanting to teach online so that she could reduce her teaching workload but came to realize that "online classes are very demanding" and "would even argue that online courses are more demanding [than face-to-face courses]."

The instructors also appeared to model effective online instructional practices and presence in ways that helped participants expand their vision of what their responsibilities would be as online instructors. Participant 1 stated in her interview, "[The instructor's] personality, his knowledge- all of that helped to change my views around online learning." When watching her instructors' weekly orientation videos, Participant 11 recalled thinking, "Oh, I could totally do this. I should do this more." Instructor-created videos also modeled to Participant 14 that "it's okay to make mistakes on videos. It's okay to play. It's okay to be goofy and seem more human." Similarly, many discussion board participants expressed discomfort when creating videos that showed their faces, but their experiences in the course helped them realize that "it is an important part of building trust and community with the students."

Receiving video feedback from their instructor appeared to be particularly "transformative" and "changed the way [participants] looked at providing feedback to students." Participant 13 stated, "Video feedback ... opened a whole new world of working with student learners in an online setting. ... I totally view [feedback] differently." In fact, at the time of her interview, Participant 13 had already begun to provide her students with video feedback:

It's so much faster! That was sort of a duh moment, you know. You should have thought about that before because I can talk faster than I can write it and my feedback was much more explicit and the students came back and said, "Oh thank you! Now I see exactly what you mean."

Participants were also surprised at the level of community they were able to form with the instructor and other course participants. Participant 3 explained in her interview that she recently completed a different online training that was "very dry" and simply required participants to read materials and take quizzes. As a result, that was her "perception of what online learning was." She explained that her interactions with others in the course changed her perceptions of online learning: "We developed a community that I didn't think, honestly, was possible through online [learning]." Similarly, Participant 11 had a prior misconception that there "was a lack of interaction, getting to know people, students, or the instructor" in online courses but found that developing a sense of community was "pretty intuitive once you're shown and told how you can foster that."

Discussion board comments reflected similar sentiments. One read, "The fact that an online version of a class is not just a narrated [presentation] made a big impact on how I rated the quality of my courses." Another added that she was surprised that there were "so many ways that allow students and instructors to show who they are." Similarly, one discussion board participant stated, "[The instructor] did a fabulous job of building a sense of community among our little group in such a short time. I really want to be able to do that with my students too." Several recalled feeling 
uncomfortable or even "scared" to create a webcam video for the icebreaker activity but quickly became more comfortable. One discussion board participant wrote, "I can't say that I'm totally comfortable, however watching [the instructor] be 'natural' with his videos for this class, hearing and seeing other teachers do their videos has been very relieving and rewarding." Another previously believed that learning online was "primarily an individual endeavor" but came to realize "online course environment can be a richer avenue for peer collaboration than in the classroom."

\section{Discussion}

In this case study, we collected and analyzed survey responses, discussion board comments, and end-of-course interviews to better understand how a 5- to 6-week online teaching initiative impacted faculty participants' knowledge and skills to teach online and their perceptions towards online learning. In this section, we discuss our findings in the context of previous research and highlight practical implications for those interested in preparing faculty to teach online.

\section{Improvements to Participants' Knowledge and Skills}

The improvements in participants' TPACK on the pre- and postcourse survey were consistent with previous research (Rienties, Brouwer, \& Lygo-Baker, 2013; Rienties et al., 2013). While TK scores did not change as much, this result could be attributed to the large variability of scores within a small sample size. Those participants who came with advanced TK reported that the OTI course helped them delve deeper and expand their tool menus. Regardless of their TK levels, the participants had the largest increases in overall TPACK scores, demonstrating improvements in their general confidence to teach online (Rienties, Brouwer, \& Lygo-Baker, 2013). Overall, this finding supports the need for adequate professional development programs in higher education institutions, especially for those who are less experienced in online teaching (Gachago et al., 2017; Meyer \& Murrell, 2014).

While the OTI course appeared largely successful in improving participants' readiness to teach online, some important limitations to the course should be addressed. For those with limited technological experiences, the learning curve was steep and, at times, overwhelming, an observation which is consistent with previous research (Reilly et al., 2012). Gee (2004) argued,

Learning works best when new challenges are pleasantly frustrating in the sense of being felt by learners to be at the outer edge of, but within, their "regime of competence." That is, these challenges feel hard, but doable. (p. 19)

While professional development should prove challenging and even perhaps frustrating at times, facilitators should work to ensure that participants are not overwhelmed. More research is needed to examine how learning activities and projects can be adapted based on participants' ability levels. For some in the OTI course, it felt overwhelming to remember all the tools and resources shared in the course. In fact, in one section students requested and then created a resource table. Similarly, some course completers did not feel fully prepared to teach online and requested additional professional development materials and courses. Just as professional development course facilitators work to onboard participants and develop a learning community, they should also extend resources and opportunities when the course ends.

It also appeared especially important that the OTI course modeled best online teaching practices that allowed faculty to experience quality online learning from a student's perspective (Elliott et al., 2015; Ginzburg et al., 2010). It demonstrates to faculty that online teaching can be 
engaging, interactive, and student centered (Garrison, 2009). In addition to improving knowledge and skills, professional development in an online format can improve faculty confidence and selfefficacy to teach online (Brooks, 2010; Ginzburg et al., 2010; Rienties, Brouwer, \& Lygo-Baker, 2013; Reilly et al., 2012). This was apparent in our study. Participants attributed their perceived improvements in knowledge, skills, and perceptions to exemplars and models provided in the OTI course, as well as to peer interactions.

Once again, the important ingredient is not putting professional development materials online; rather, it is modeling best practices. As one participant in this study noticed, online modules with limited interaction might result in instructors' perception that online learning is all about posting materials and setting up quizzes. Thus, it is essential for facilitators to "practice what they preach" (Elliott et al., 2015) and model the alignment between learning objectives, activities, and assessments. Based on the findings in this study, learning from observation as well as from social interactions seems to transform instructors' beliefs and attitudes (Bandura, 1997; Gachago et al., 2017), which, in turn, may result in increased long-term effectiveness in online teaching and ability to model best practices to pre- and in-service teachers (Ertmer, 2005).

Given the importance of modeling, the large prevalence of face-to-face professional development for online teaching is surprising (Meyer \& Murrell, 2014). An additional benefit of online professional development is its availability. An online, especially asynchronous, format allows flexible (although structured) scheduling and increases instructors' participation. It also makes these training opportunities available to adjunct instructors, who might not have easy access to face-to-face training on campus (Elliott et al., 2015).

\section{Practical Implications}

Online professional development programs that model high-quality online teaching and learning offer an effective and efficient environment for instructors to update their skills and beliefs (Gachago et al., 2017; Walters et al., 2017). Based on our findings, it is important to design a program that matches the learning formats, topics, and technological resources available to those who will enroll. It might be beneficial to conduct the basic needs assessment before developing an online training program (Ginzburg et al., 2010). While some research indicates that a flexible timeline gives participants autonomy to finish the work at their convenience (Rienties, Brouwer, \& Lygo-Baker, 2013), our study suggested that deadlines were important for maintaining an adequate learning pace similar to that which students typically experience. Perhaps more importantly, the weekly deadlines allow participants to engage in meaningful discussions and collaboration, which appeared to be an important aspect of the course.

It has also been beneficial for our participants to keep course materials available even after the program has ended, so they can continue to practice and revisit the information when teaching actual online courses. During the program, it is essential to provide exemplars; encourage exploration or "play" time with various technologies; model best practices of online teaching; promote collaboration between homogeneous cohorts (from similar fields at the same level of technological and teaching expertise) or heterogeneous cohorts (from different disciplines or from more experienced or beginner groupings); and encourage reflection and self-assessment.

Similar to earlier research (Jones, Hope, \& Adams, 2018), we found that faculty were motivated by the digital badges they earned in the course. Other studies have also described professional development that motivated instructors to complete the work using micro credentialing in the form of digital badges (Dyjur \& Lindstrom, 2017). As a result, when designing 
extended professional development where attrition may be an issue, digital badges may motivate some faculty to persist and finish a course. Consistent with previous research (Dyjur \& Lindstrom, 2017), we found that more explicit explanations of what to do with those badges are needed. It is also important that if badges are offered, they are earned, not simply given for attendance. Research has found that employers value badges awarded for demonstrated skills more than participationbased badges (Carey \& Stefaniak, 2018). In fact, West and Randall (2016) argued that the biggest threat to the badging community is that badges are too often awarded simply for attendance, and if more badges are not linked to rigorous assessments, the movement will simply be a fun diversion that has no meaningful impact.

\section{Conclusion}

As online learning grows in K-12 and higher education, the need to prepare quality online instructors increases. The need for quality online instructors is especially important in colleges of education because preservice and in-service teachers require online instructor models to help them learn what is possible in the online environment. However, preparing college of education faculty requires developing their online teaching skills and knowledge (first-order barriers to change) and nurturing positive attitudes and dispositions (second-order barriers to change). This case study found that a 6- or 7-week professional development online course focused on teaching online was effective at overcoming first- and second-order barriers to change. More specifically, the course content and assignments proved effective at increasing faculty members' knowledge and skills, but it was the course delivery and the opportunity to learn as an online student that appeared to most impact faculty members' attitudes and perceptions of what was possible in online learning environments. In other words, the method was just as important as the message. When designing professional development courses, universities not only need to consider what will be learned but how it will be learned. If courses do not model effective online instruction, they run the risk of increasing faculty members' skills without improving their practice.

\section{Recommendations for Future Research}

This study included a small set of participants; thus, while insightful, the findings cannot be generalized and should be considered only within the context of this research. One major limitation involves the reliance on self-reported measures of instructors' knowledge and attitudes. It is unclear whether the changes in online teaching knowledge and skills we found were perceived or actual. This is consistent with previous research that focused on satisfaction rather than observable changes (Rienties et al., 2013). Future studies might incorporate some observational measures to determine how much newly acquired knowledge instructors actually transfer to their online learning environments. Longitudinal studies of instructors' online teaching practices after completing an online professional development program could also be helpful in understanding its long-term effects. Finally, this study focused only on the instructors. Future research may benefit from including student measures (when appropriate) to see if changes in instructors' knowledge, skills, attitudes, and perceptions actually resulted in improved student outcomes. Seeing measurable benefits for students would likely further inspire instructors to shift their beliefs and seek opportunities for high-quality professional development. While challenging, this expanded research could provide important insights colleges of education better prepare faculty to teach online. In turn, modeling effective online teaching practices has been shown to help preservice teachers expand their understanding of what is possible in online courses. 


\section{References}

Allen, I. E., \& Seaman, J. (2017). Digital learning compass: Distance education enrollment report 2017. Babson Survey Research Group. Retrieved from http://onlinelearningsurvey.com/reports/digtiallearningcompassenrollment2017.pdf

Anderson, T. (2009). A rose by any other name: Still distance education - a response to D. R. Garrison: Implications of online and blended learning for the conceptual development and practice of distance education. Journal of Distance Education, 23(3), 111-116.

Archambault, L., \& Barnett, J. H. (2010). Revisiting technological pedagogical content knowledge: Exploring the TPACK framework. Computers \& Education, 55(4), 16561662.

Archambault, L., \& Crippen, K. (2009). Examining TPACK among K-12 online distance educators in the United States. Contemporary Issues in Technology and Teacher Education, 9(1), 71-88.

Bandura, A. (1977). Self-efficacy: The exercise of control. New York: Freeman.

Bandura, A. (1986). Social foundations of thought and action. Englewood Cliffs, NJ: PrenticeHall.

Bandura, A., \& Kupers, C. J. (1964). Transmission of patterns of self-reinforcement through modeling. Journal of Abnormal and Social Psychology, 69(1), 1-9.

Baran, E., Correia, A.-P., \& Thompson, A. (2011). Transforming online teaching practice: Critical analysis of the literature on the roles and competencies of online teachers. Distance Education, 32(3), 421-439. https://doi.org/10.1080/01587919.2011.610293

Barbour, M. K. (2012). Training teachers for a virtual school system: A call to action. In D. Polly, C. Mims, \& K. Persichitte (Eds.), Creating technology-rich teacher education programs: Key issues (pp. 499-517). Hershey, PA: IGI Global.

Bigatel, P. M., Ragan, L. C., Kennan, S., May, J., \& Redmond, B. F. (2012). The identification of competencies for online teaching success. Journal of Asynchronous Learning Networks, 16(1), 59-78.

Brooks, C. F. (2010). Toward 'hybridised' faculty development for the twenty-first century: Blending online communities of practice and face-to-face meetings in instructional and professional support programs. Innovations in Education and Teaching International, 47(3), 261-270. doi:10.1080/14703297.2010.498177

Carey, K. L., \& Stefaniak, J. E. (2018). An exploration of the utility of digital badging in higher education settings. Educational Technology Research and Development, 66(5), 12111229. https://doi.org/10.1007/s11423-018-9602-1

Dyjur, P., \& Lindstrom, G. (2017). Perceptions and uses of digital badges for professional learning development in higher education. Tech Trends, 61, 386-392.

Elliott, M., Rhoades, N., Jackson, C. M., \& Mandernach, B. J. (2015). Professional development: Designing initiatives to meet the needs of online faculty. Journal of Educators Online, $12,160-188$. 
Ertmer, P.A. (1999). Addressing first- and second-order barriers to change: Strategies for technology integration. Educational Technology Research and Development, 47(4), 4761.

Ertmer, P.A. (2005). Teacher pedagogical beliefs: The final frontier in our quest for technology integration? Educational Technology Research and Development, 53(4), 25-39.

Gachago, D., Morkel, J., Hitge, L., van Zyl, I., \& Ivala, E. (2017). Developing eLearning champions: A design thinking approach. International Journal of Educational Technology, 14(1), 1-14. doi:10.1186/s41239-017-0068-8.

Garrison, R. (2009). Implications of online learning for the conceptual development and practice of distance education. Journal of Distance Education, 23(2), 93-104.

Garrison, D. R., Anderson, T., \& Archer, W. (2000). Critical inquiry in a text-based environment: Computer conferencing in higher education. The Internet and Higher Education, 2(2-3), 87-105. https://doi.org/10.1016/S1096-7516(00)00016-6

Gee, J. P. (2008). Good video games + good learning: Collected essays on video games, learning and literacy. Washington, DC: Peter Lang Publishing.

Gemin, B., \& Pape, L. (2017). Keeping pace with K-12 online learning 2016. Evergreen Education Group. Retrieved from http://files.eric.ed.gov/fulltext/ED576762.pdf

Ginzburg, E., Chepya, P., \& Demers, D. (2010). The digital learning faculty certificate program. International Journal on E-Learning, 9, 313-324.

Glaser, B. G. (1965). The constant comparative method of qualitative analysis. Social Problems, 12(4), 436-445.

Gosselin, K. P., Northcote, M., Reynaud, D., Kilgour, P., Anderson, M., \& Boddey, C. (2016). Development of an evidence-based professional learning program informed by online teachers' self-efficacy and threshold concepts. Online Learning, 20, 178-194.

Graham, C. R. (2011). Theoretical considerations for understanding technological pedagogical content knowledge (TPACK). Computers \& Education, 57(2011), 1953-1969. https://doi.org/10.1016/j.compedu.2011.04.010

Graham, C. R., Borup, J., \& Smith, N. B. (2012). Using TPACK as a framework to understand teacher candidates' technology integration decisions. Journal of Computer Assisted Learning, 28(6), 530-546. https://doi.org/10.1111/j.1365-2729.2011.00472.x

Jones, W. M., Hope, S., \& Adams, B. (2018). Teachers' perceptions of digital badges as recognition of professional development. British Journal of Educational Technology, 49(3), 427-438. https://doi.org/10.1111/bjet.12557

Johnson, T., Wisniewski, M. A., Kuhlemeyer, G., Isaacs, G., \& Krzykowski, J. (2012). Technology adoption in higher education: Overcoming anxiety through faculty bootcamp. Journal of Asynchronous Learning Networks, 16, 63-72.

McAllister, L., \& Graham, C. R. (2016). An analysis of the curriculum requirements for K-12 online teaching endorsements in the U.S. Journal of Online Learning Research, 2(3), $247-282$. 
McQuiggan, C. A. (2012). Faculty development for online teaching as a catalyst for change. Journal of Asynchronous Learning Networks, 16, 27-61.

Merriam, S. B. (1998). Qualitative research and case study applications in education: Revised and expanded from case study research in education. San Francisco, CA: Jossey-Bass.

Meyer, K. A., \& Murrell, V. S. (2014). A national study of training content and activities for faculty development for online teaching. Journal of Asynchronous Learning Networks, $18,3-18$.

Mishra, P., \& Koehler, M. J. (2006). Technological pedagogical content knowledge: A framework for teacher knowledge. Teachers College Record, 108(6), 1017-1054.

Moore, M. G. (1989). Editorial: Three types of interaction. The American Journal of Distance Education, 3(2), 1-6.

Norton, P., \& Hathaway, D. (2015). Teachers' online experience: Is there a covert curriculum in online professional development? Journal of Technology and Teacher Education, 23, 509-533.

Park, G. J., Johnson, H. J., Vath, R. J., Kubitskey, B. W., \& Fishman, B. J. (2013). Examining the roles of the facilitator in online and face-to-face PD contexts. Journal of Technology and Teacher Education, 21(2), 225-245.

Reilly, J. R., Vandenhouten, C., Gallagher-Lepak, S., \& Ralston-Berg, P. (2012). Faculty development for e-learning: A multi-campus community of practice (COP) approach. Journal of Asynchronous Learning Networks, 16, 99-110.

Rhode, J., Richter, S., \& Miller, T. (2018). Designing personalized online teaching professional development through self-assessment. TechTrends, 51, 444-451.

Rienties, B., Brouwer, N., Bohle Carbonell, K., Townsend, D., Rozendal, A-P., van der Loo, J., ... Lygo-Baker, S. (2013). Online training of TPACK skills of higher education scholars: A cross-institutional impact study. European Journal of Teacher Education, 36, 480-495. doi:10.1016/j.tate.2012.09.002

Rienties, B., Brouwer, N, \& Lygo-Baker, S. (2013). The effects of online professional development on higher education teachers' beliefs and intentions towards learning facilitation and technology. Teaching and Teacher Education, 29, 122-131. doi:10.1016/j.tate.2012.09.002

Roby, T., Ashe, S., Singh, N., \& Clark, C. (2013). Shaping the online experience: How administrators can influence student and instructor perceptions through policy and practice. The Internet and Higher Education, 17, 29-37.

Schrum, L., Burbank, M. D., Engle, J., Chambers, J. A., \& Glassett, K. F. (2005). Post-secondary educators' professional development: Investigation of an online approach to enhancing teaching and learning. Internet and Higher Education, 8, 279-289.

Shulman, L. S. (1986). Those who understand: Knowledge growth in teaching. Educational Researcher, 15(2), 4-14. Retrieved from http://www.jstor.org/stable/1175860

Signer, B. (2008). Online professional development: Combining best practices from teacher, technology, and distance education. Journal of In-Service Education, 34, 205-218. 
Stake, R. E. (2010). Qualitative research: Studying how things work. New York, NY: Guilford Press.

Swan, K., Garrison, D. R., \& Richardson, J. C. (2009). A constructivist approach to online learning: The Community of Inquiry framework. In C. R. Payne (Ed.), Information technology and constructivism in higher education: Progressive learning frameworks (pp. 43-57). Hershey, PA: IGI Global.

Walters, S., Grover, K. S., Turner, R. C., \& Alexander, J. C. (2017). Faculty perceptions related to teaching online: A starting point for designing faculty development initiatives. Turkish Online Journal of Distance Education, 18(4), 4-19.

Wang, M. (2007). Designing online courses that effectively engage learners from diverse cultural backgrounds. British Journal of Educational Technology, 38, 294-311.

West, R. E., \& Randall, D. L., (2016). The case for rigor in open badges. In L. Y. Muilenburg and Z. L. Berge (Eds.), Digital badges in education: Trends, issues, and cases. Routledge: New York, NY.

Wingo, N. P., Peters, G. B., Ivankova, N. V., \& Gurley, D. K. (2016). Benefits and challenges of teaching nursing online: Exploring perspectives of different stakeholders. The Journal of Nursing Education, 55, 433-440.

Wolcott, H. F. (1994). Transformative qualitative data: Description, analysis, and interpretation. Thousand Oaks, CA: Sage Publications.

Woodworth, J. L., Raymond, M. E., Chirbas, K., Gonzalez, M., Negassi, Y., Snow, W., \& Van Donge, C. (2015). Online charter school study. Stanford, CA. Retrieved from https://credo.stanford.edu/pdfs/OnlineCharterStudyFinal2015.pdf 